\title{
The improvement in management of material and production reserves of the enterprise in conditions of uncertainty using the fuzzy sets
}

\author{
M.I. Raskatova ${ }^{1, *}$, and E.B. Golovanov ${ }^{1}$ \\ ${ }^{1}$ South Ural State University, Chelyabinsk, Russia
}

\begin{abstract}
In the article a method of management of material and production reserves of industrial enterprises in conditions of uncertainty has been suggested. The method proposes that a part of a benchmark in economic and mathematical models of determining the volume and completion time for orders for raw products and materials be represented as fuzzy numbers. The application of fuzzy-set theory allows taking into account the uncertainty of the external environment without using the theory of probability. The use of the latter is often difficult. The criterion for choosing the optimal management strategy is the minimization of the objective function of the total cost connected with reserves management. It is suggested to obtain the benchmarks that are expressed by fuzzy numbers with a method of expert evaluation. Using the results obtained with the suggested approach the decision-maker will be able to form a concrete strategy for reserves management in a constantly changing market situation. The suggested technique is universal; its application is possible in various industries.
\end{abstract}

\section{Introduction}

Nowadays in the conditions of market economy at industrial enterprises increasingly more attention is paid to improving the system of supply and, in particular, management of material and production reserves, which have a significant share in the cost of finished products production. One would think that much has already been said on the topic of reserves management. There is a large number of methods and models of reserves management. However, determinate models are good for studying this question in a theoretical aspect. In reality enterprises operate in a market environment which is uncertain. In these cases, the management quality can and should be improved just through the use of models that take into account uncertainties. Today the first and the most common method of taking into account the uncertainty is the theory of probability. However, the application of methods of probability is difficult and not always possible due to the high complexity, and often due to the impossibility of collecting all the necessary information on nomenclature of thousands of materials that are used at the enterprise. In addition, when collecting data in a representative volume, conditions of statistical stability and permanence of the situation are necessary, which is impossible, because all enterprises operate in a constantly changing external environment.

Since methods of the theory of probability have such limits, then the question arises: is there any method which allows avoiding these limits?

We suggest moving from the classical formulation of the reserves management problem in which all the parameters are expressed in terms of familiar to us distinct numbers to the same crucial task, but which is formulated and solved using tools of fuzzy sets (fuzzy logic).

\section{Main part}

Scientists have been preoccupied with problems that concern reserves management for quite a long time. In the twentieth century a large number of methods and reserves management models in determinate and nondeterminate conditions were developed [1-8].

In the case when all parameters are set exactly (determinate case), it has the following formulation. Enterprises created a certain amount of material and production reserves which contributes to their non-stop operation. From time to time it is required to replenish reserves. It is necessary to determine the frequency of orders and the size of orders of raw products and materials. A large number of reserves leads to high costs for their storage and freezing of assets, ordering small quantities leads to higher transportation costs. The lack of material and production reserves at the enterprise can lead to a stoppage in production. It is required to determine the optimal reserves management strategy (volumes of orders and frequency of orders), ensuring minimization of the total cost of the establishment and replenishment of a reserve during the planning period.

We suggest using methods of dynamic programming as instruments in order to solve the problem where the decision-making process is divided

\footnotetext{
Corresponding author: mirru@yandex.ru
} 
into separate stages (steps) [9,10], and simulation modeling $[10,11]$ that allows to simulate various options and to determine the range of acceptable strategies of management of material and production reserves of industrial enterprises that satisfy the limit system. A choice criterion of the optimal strategy is the minimum of the objective function of the total costs connected with reserves management.

$$
F^{r}=\sum_{j=1}^{N} Z_{j}^{r} \rightarrow \min , j=1, \ldots, N
$$

where $Z_{j}^{r}$ - total cost, that appears during j-amount of time in the case of a strategy implementation $r$.

Total costs consist of five kinds of costs that have the greatest influence on the formation of the delivery plan. These include resource acquisition costs, transportation costs, reserves storage, ordering and costs, caused by the binding of circulating assets (lost profit).

For the purpose of making effective decisions in reserves management of the enterprise in conditions of instability and uncertainty in the external environment in this mathematical model one cluster is added that allows to work with fuzzy benchmarks using the fuzzyset theory [12-14]. Since the mid-twentieth century the widespread use of models has been started that are based on fuzzy logic in industries from home appliances and to management of complex technological systems and dynamic objects (robots, airplanes, cars, etc.) [15].

The use of the fuzzy logic in solving economic problems is not yet sufficiently widespread. Russian scientists are considering the application of fuzzy-set theory in solving problems of assessing the financial condition of the company, assessment of efficiency of the investment project, risk assessment of the securities portfolio of investment [17-20].

In its application in the management of enterprises a triangular type of a fuzzy number is often used as predictive numbers of benchmarks, in which the most expected value of the parameter (the top of the triangle) and the range of variation of this value (the base of the triangle) are set. The corresponding triangular number $\mathrm{X}$ is being written in the following form: $\mathrm{X}=\left(x_{l}, \bar{x}\right.$, $x_{r}$ ), where $\bar{x}$ is the expected value of a fuzzy number (a real number) , $x_{l}$ and $x_{r}$ are respectively the left and right borders of the fuzzy number (real numbers) [14]. In economics the method of extraction of three significant points of benchmarks is often used. Often the pessimistic, most probable and optimistic scenarios of the solution are considered to be these points. However, in this case subjective probabilities are used, the actual value of which can neither be defined nor assigned [20]. In this regard, we suggest using the fuzzy-sets theory, which allows replacing the notion of randomness with the notions of possibility and expectation.

\section{A method of optimal reserves management of raw products and materials}

Our suggested method of optimal reserves management of raw products and materials, mediated in the developed economic-mathematical model consists of the following steps:

1. Benchmarks collection.

The benchmark in the model is presented in two forms: distinct and fuzzy. Distinct benchmarks are: the value of safety stock, maximum storage capacity of a warehouse, initial and final reserves of material in a warehouse, cost of storage unit, the capacity of one transport unit, the minimum and maximum delivery amounts.

The benchmarks expressed by fuzzy numbers are the expected demand for materials in each time interval, the expected price of the material and the expected cost of transportation by one vehicle. These data were obtained with the method of expert evaluation.

2. Preparing the total of benchmarks obtained on the basis of an experts survey.

3. Carrying out calculations according to the model of reserves management that is discussed above.

The result of the calculation is the optimal strategy for reserves management, i.e., amounts of orders and time for order replenishment. The criterion for choosing the optimal strategy is the minimization of the total cost over the entire planning period.

4. Since some benchmarks of the studied model of reserves management are suggested to be presented in the fuzzy form, the results of the calculations are fuzzy as well. There are a lot of ways of converting fuzzy numbers into distinct ones $[21,22]$. We suggest providing a solution in the form of a fuzzy number, thus, it helps to avoid simplifications and the loss of some information during the transition to a clearly determinate solution. On the basis of the findings and recommendations, the decision-maker can use his experience, knowledge, information, that are not considered in the model and he can form a specific strategy for reserves management.

However, in order to ensure that the employee, who does not possess the knowledge of fuzzy sets, could make decisions on the basis of the suggested model, the program has a defuzzification stage, i.e. conversion of fuzzy numbers into a familiar distinct form. In the practice of the application of the suggested method conversion of fuzzy values into distinct order amounts is the most appropriate on the basis of total vehicle load, which will allow reducing the cost of transportation.

\section{Results and discussion}

Approbation of our developed model has been carried out on one group of furniture enterprises of Chelyabinsk, and in particular on CJSC Factory of special joinery "Cabinetmaker". 
Table 1. The expected requirements of a MDF pack $10 \mathrm{~mm}$.

\begin{tabular}{|c|c|c|c|c|c|c|c|c|c|}
\hline \multirow{2}{*}{$\begin{array}{c}\text { Time } \\
\text { intervals }\end{array}$} & \multicolumn{3}{|c|}{ Expert 1 } & \multicolumn{3}{c|}{ Expert 2 } & \multicolumn{3}{c|}{ Expert 3 } \\
\cline { 2 - 11 } & $\begin{array}{c}\text { beft } \\
\text { border }\end{array}$ & $\begin{array}{c}\text { Average } \\
\text { number }\end{array}$ & $\begin{array}{c}\text { Right } \\
\text { border }\end{array}$ & $\begin{array}{c}\text { Left } \\
\text { border }\end{array}$ & $\begin{array}{c}\text { Average } \\
\text { number }\end{array}$ & $\begin{array}{c}\text { Right } \\
\text { border }\end{array}$ & $\begin{array}{c}\text { Left } \\
\text { border }\end{array}$ & $\begin{array}{c}\text { Average } \\
\text { number }\end{array}$ & $\begin{array}{c}\text { Right } \\
\text { border }\end{array}$ \\
\hline 1 & 31 & 33 & 36 & 31 & 34 & 36 & 30 & 33 & 36 \\
\hline 2 & 30 & 33 & 36 & 31 & 34 & 37 & 30 & 33 & 36 \\
\hline 3 & 31 & 34 & 35 & 29 & 33 & 36 & 30 & 33 & 35 \\
\hline 4 & 30 & 32 & 35 & 30 & 33 & 37 & 29 & 33 & 36 \\
\hline 5 & 28 & 29 & 31 & 27 & 31 & 34 & 30 & 33 & 36 \\
\hline 6 & 31 & 33 & 36 & 29 & 33 & 36 & 31 & 34 & 37 \\
\hline 7 & 31 & 34 & 37 & 32 & 34 & 37 & 31 & 34 & 37 \\
\hline 8 & 30 & 33 & 34 & 30 & 33 & 37 & 31 & 34 & 37 \\
\hline
\end{tabular}

For this purpose, at the enterprise a group of experts was established, including the head of procurement department, the head of production and warehouse. They provided with the data on the expected material requirements in each time interval, on the expected price of the material and on the expected cost of transportation by one vehicle that areexpressed by fuzzy numbers, i.e. experts set the less expected, the most probable and the most expected value of the indicator.

On the basis of the provided by experts data with the help of additional information regarding the value of safety stock, the maximum storage capacity of a warehouse, the initial and final stocks of material in the warehouse, the cost of a storage unit, the capacity of one transportation unit, the minimum and maximum delivery amounts, the optimal strategy of reserves management has been determined, i.e. delivery amounts and time of replenishment has been found. As an example there are survey data belonging to three experts of CJSC Factory of special joinery
"Cabinetmaker" regarding the expected requirements of MDF $10 \quad \mathrm{~mm}$ (table 1). The amount of the considered time interval is one week.

In the same way the experts expressed their opinions on two other indicators which are presented in the model in the fuzzy form: the expected price of a MDF pack $10 \mathrm{~mm}$ and the expected cost of transportation by one vehicle. Then using the algorithm for calculation of the generalized expert evaluations $[23,24]$ the total of benchmarks has been prepared (table 2). The results of calculations are listed with the help of the suggested model of reserves management in table 3 .

It is clear that the most expected value of the minimum cost of the purchased MDF material $10 \mathrm{~mm}$ will be 15665070 rubles. In the conditions of uncertainty of the benchmarks the variation of the total cost will be from 14832432 rubles up to 16525 086 rubles. CJSC "Cabinetmaker" orders $34 \mathrm{MDF}$ packs every week. This will cost 16382435 rubles for 2 months ( 8 time intervals).

Table 2. The expected MDF $10 \mathrm{~mm}$, packs.

\begin{tabular}{|c|c|c|c|c|c|c|c|c|c|}
\hline \multirow{2}{*}{$\begin{array}{c}\text { Time } \\
\text { intervals }\end{array}$} & \multicolumn{2}{|c|}{ Requirements, number of packs } & \multicolumn{2}{|c|}{ The price of a MDF pack, rubles } & \multicolumn{3}{|c|}{ Transportation cost, rubles } \\
\cline { 2 - 11 } & $\begin{array}{c}\text { Left } \\
\text { border }\end{array}$ & $\begin{array}{c}\text { Average } \\
\text { number }\end{array}$ & $\begin{array}{c}\text { Right } \\
\text { border }\end{array}$ & $\begin{array}{c}\text { Left } \\
\text { border }\end{array}$ & $\begin{array}{c}\text { Average } \\
\text { number }\end{array}$ & $\begin{array}{c}\text { Right } \\
\text { border }\end{array}$ & $\begin{array}{c}\text { Left } \\
\text { border }\end{array}$ & $\begin{array}{c}\text { Average } \\
\text { number }\end{array}$ & $\begin{array}{c}\text { Right } \\
\text { border }\end{array}$ \\
\hline 1 & 31 & 34 & 36 & 42842 & 45277 & 47260 & 56700 & 59128 & 61544 \\
\hline 2 & 31 & 35 & 36 & 43072 & 45677 & 46980 & 56875 & 59560 & 62226 \\
\hline 3 & 30 & 34 & 35 & 42672 & 45140 & 47630 & 57720 & 60317 & 62856 \\
\hline 4 & 30 & 33 & 36 & 42842 & 45473 & 47365 & 56780 & 59060 & 61340 \\
\hline 5 & 28 & 34 & 35 & 42334 & 44944 & 46348 & 56802 & 59435 & 62382 \\
\hline 6 & 30 & 33 & 36 & 43372 & 44344 & 47513 & 56436 & 59724 & 61582 \\
\hline 7 & 31 & 34 & 37 & 43405 & 45507 & 45346 & 57284 & 59350 & 62383 \\
\hline 8 & 31 & 33 & 37 & 43338 & 44643 & 46750 & 57648 & 60340 & 62765 \\
\hline
\end{tabular}


Table 3. The delivery plan of mdf sheets 10 mm, packs.

\begin{tabular}{|c|c|c|c|}
\hline Time interval & $\begin{array}{c}\text { Left } \\
\text { border }\end{array}$ & $\begin{array}{c}\text { Average } \\
\text { number }\end{array}$ & $\begin{array}{c}\text { Right } \\
\text { border }\end{array}$ \\
\hline 1 & 31 & 33 & 36 \\
\hline 2 & 31 & 33 & 35 \\
\hline 3 & 60 & 65 & 67 \\
\hline 4 & 0 & 0 & 0 \\
\hline 5 & 68 & 72 & 73 \\
\hline 6 & 0 & 0 & 0 \\
\hline 7 & 64 & 67 & 69 \\
\hline 8 & 0 & 0 & 0 \\
\hline $\begin{array}{c}\text { General costs, } \\
\text { rubles }\end{array}$ & 14832432 & 15665070 & 16525086 \\
\hline
\end{tabular}

The total cost that corresponds to the delivery plan, calculated with the help of the model for the same time period will be 15665070 rubles. Thus, the suggested strategy will reduce the cost to 717365 rubles, or by $4.6 \%$. When considering the annual interval the cost saving will be about 4300 thousand rubles in the absence of major changes in production amounts, prices, etc.

\section{Conclusion}

The suggested method can calculate storage requirements in other materials that are necessary for the manufacturing process in the factory. The suggested model and methodology are universal; their application is possible at industrial enterprises of other industries.

Thus, the activities of industrial enterprises in a market economy are strongly influenced by the instability and uncertainty of the environment. Therefore, one of the most urgent problems of improving reserves management of raw products and materials at enterprises is finding solutions that take into account the conditions of uncertainty using fuzzyset approach.

Application of the developed method allows reducing the costs of reserves management which will ultimately lead to an improvement in the overall efficiency of the enterprise.

The implementation of a new methodological approach to the reserves management of raw products and materials will contribute to the growth of efficiency in industry, as an instrument of tactical and strategic enterprise management.

The work was supported by Act 211 Government of the Russian Federation, contract № 02.A03.21.0011.

\section{References}

1. A.M. Zevakov, Logistics of material reserves and financial assets (Piter, Saint-Petersburg, 2005)

2. K. Lysons, M. Gillingham, Purchasing and supply chain management (Infra-M, Moscow, 2005)
3. Michael R. Leenders, Harold E. Fearon, Purchasing and supply management (Victoria plus Ltd, SaintPetersburg, 2002)

4. V.A. Lototsky, A.S. Mandel, Models and methods of supply management (Science, Moscow, 1991)

5. S.R. Mikityants, N.N. Goldobina, Application of mathematical methods in supply management (LSEI, Leningrad, 1982)

6. G.B. Roubalsky, Probabilistic and computational methods of optimal supply management (Knowledge, Moscow, 1987)

7. Oliver W. Wight, Production and inventory management (Progress, Moscow, 1978)

8. G. Hadley, Thomson M. Whitin, Analysys of inventory systems (Science - Physmath, Mocsow, 1969)

9. N.Sh. Kremer, I.M. Trishin, M.N. Fridman, Operations research in economics: teaching aid for institutes of higher education (Banks and Exchanges, UNITY, Moscow, 1997)

10. I.L. Kalihman, M.A. Voitenko, Dynamic programming (Higher school, Moscow, 1979)

11. Robert E. Shannon, Systems simulation modelling arts and science (Mir, Moscow, 1978)

12. A. Kofman, Alukha Kh. Khil, Introduction to the theory of fuzzy sets in the management of enterprises (Vusheyshaya shkola, Minsk, 1992)

13. A.O. Nedosekin, Methodological basis of financial activities modelling applying fuzzy-multiple descriptions (Saint-Petersburg, 2003)

14. L.A. Zadeh, Fuzzy Sets and Systems, 1, 1 (1978)

15. M.I. Raskatova, Bulletin of Chelyabinsk state university. Series: Economics, 5, 119-126 (2007)

16. M. Hudec, Proc. Information, Communication and Automation Technologies (ICAT), 1-6 (2015)

17. R.J. Almeida, N. Basturk, U. Kaymak, Proc. Computational Intelligence for Financial Engineering \& Economics (CIFEr), 497-504 (2014)

18. V.P. Meshalkin, A.Y. Belozersky, Transport business in Russia, 2, 189-191 (2011)

19. J. Grable, R.H. Lytton, Financial Services Rewiew, 8, 163-181 (1999)

20. A.O. Nedosekin, Audit and finfncial analysys, 2, 138-161 (2000).

21. S.V. Matsievsky, Fuzzy set: a teaching aid (KSU, Kaliningrad, 2004)

22. A.N. Borisov, O.A. Kroumberg, I.P. Fedorov, Decision-making on the basis of fuzzy models: examples of application (Zinatie, Riga, 1990)

23. P. Jackson, Introduction to expert systems (Publishing house "Wiliams", Moscow, 2001)

24. L.G. Evlanov, V.A. Koutouzov, Expert judgements in management (Econoimics, Moscow, 1978) 